\title{
The application potential of mobile excursion applications for the rural tourism development in the Rostov region
}

\author{
Lyudmila Kazmina ${ }^{1}$,Elena Shevchenko ${ }^{1,{ }^{*}}$, and Vadim Makarenko ${ }^{1}$ \\ ${ }^{1}$ Don State Technical University, Gagarina Sq., 1, Rostov-on-Don, 344003, Russia
}

\begin{abstract}
The present article is concerned with usability of smartphone applications in the field of tourism and excursions to expand rural tourism in the territory of the Rostov region. Analysis of the market of smartphone touristic applications, their relevance in regard to various parameters (preferred territories, user age), geography of arrival, growth rate of user count. Recommendations on the development of smartphone application usage in the field of rural tourism with consideration of the existing possibilities and prospects.
\end{abstract}

\section{Introduction}

Smartphone applications are currently gaining in high popularity. They are actively used in various sectors, including tourism. Such applications are those innovations that make it possible to more actively develop both organized tourism, but also self-guided tours and excursions. It is especially important to develop mobile touristic applications in rural areas. In rural areas that have tourist potential, but do not have organized tourist routes and excursions, it is important to attract self-guided tourists by means of mobile applications. Rural tourism is able to have a positive effect on the development of the local economy, replenishing the budget, developing related industries (trade, public catering, transport), as well as reducing social tension through the creation of jobs.

The purpose of this article is to study the prospects for using smartphone touristic excursion applications in the development of rural tourism in the Rostov region.

The purpose of the study determines the following tasks:

- to identify the factors, conditions and prerequisites for the use of mobile applications in tourism on the territory of the Rostov region;

- to study the market of mobile touristic applications in the Rostov region;

- to analyze the age structure of users of mobile touristic applications in the region being studied, the geography and dynamics of consumer growth;

- to study consumer preferences in the field of mobile touristic applications for rural tourism;

- to identify specific limiting factors for the active usage of mobile touristic applications in rural tourism;

* Corresponding author: epetrova21@mail.ru 
- based on the data obtained, to determine the vectors for further development of mobile applications in the field of rural tourism;

- to develop practical recommendations on the enhancement of mobile touristic applications in rural tourism of the Rostov region, with consideration of the identified trends.

\section{Materials and methods}

This study is based on the papers of foreign and domestic scientists in the field of innovation in tourism, rural tourism, as well as the use of mobile applications in the tourism sector. A review of modern scientific literature shows that the role of mobile touristic and excursion applications used in smartphones is significant. Such applications facilitate access to information, contain coordinates of objects, and have audio guides and other data useful for tourists. Attraction of tourists to rural areas can be an important factor of the development of the local economy. These claims find endorsement in the papers of such authors as Sangwon Park, Yang Xu, Liu Jiang, Zhelin Chen, Shuyi Huang, Hai-Ninh Do, Wurong Shih, Quang-An Ha, Julian Reif, Dirk Schmücker, 2020 [1,2,3]. It is noted that mobile applications in the field of tourism are most actively used by young people. That is why it is preferably to develop such applications exactly for young audience and the middle-aged group, Huseyin Bicen, Saide Sadiko glu, 2016 [4]. The experience of the countries, which successfully use smartphone touristic applications Meiliana Devita, Irmanti Mochamad, Rizal Hidayat, Nur Viani, Amalina Dewi Suryani, 2017 [5] is taken into consideration. Mobile touristic applications are constantly upgraded, become more diversified and user-friendly. Comprehension and availability of smartphone applications have an indirect impact on attraction of tourists to the tourist territories, for which they were developed Chia-Chen Chen, Jia-Lun Tsai, 2019 [6].

Mobile touristic applications for smartphones are a part of the overall scope of tourism innovations. This study takes the results of academic papers on innovation in tourism in general into account. They are represented in the papers of Vanda Veréb, António Azevedo, Ángela Martínez-Pérez, Dioni Elche, Pedro M.García-Villaverde 2019, Ingrid Kofler, Anja Marcher, Michael Volgger, 2018, Beatriz Casais, Juliana Fernandes, Mariana Sarmento, 2020 [7, 8, 9, 10]. Issues on tourism innovations with regard to virtual reality are described in the paper of Myung Ja Kim, Choong-Ki Lee, Michael W.Preis, 2020 [11]. It is noted that tourism innovations influence not only the direct attraction of tourists and better services, but also systems of management of the whole industry Marcus Hansen, AnneMette Hjalager, Alan Fyall, Birgit Pikkemaat, Mike Peters, Bernhard Fabian Bichler 2019, Osnat Broshi-Chen, Yoel Mansfeld, 2021 [12, 13, 14].

Noting the need to develop tourism in rural territories, it is necessary to note the results of the studies on agritourism S. Karampela, D. Kavroudakis, T. Kizos, 2019 [15]. In the papers of several authors, it is mentioned that interest of tourists in agritourism is on the rise N.T. Farsani, S.S. Ghotbabadi, M. Altafi H, 2019, R.M. Back, A.D.A. Tasci, A. Milman, $2020[16,17]$. A review of studies on this problematics showed that measures on tourist rural territories, including the development of corresponding mobile applications, are needed for the tourism development Choo, J.F. Petrik, 2014, A.R.D. Liang, Y.Y. Nie, D.J. Chen, P-J. Chen, M.V. Vikhoreva, Yu.N. Malinina, V.A. Ogloblin, 2020 [18,19,20]. Researches on the development model are represented in the papers of M.S. Giltsova, O.A. Mironova, 2019, A.V.Truhachev, 2016 [21, 22]. Rural tourism in the Rostov region is the subject of the papers of such authors as L.N. Kazmina, V.S. Makarenko, V.V. Provotorina, T.N. Grigorenko, E. Shevchenko, A.Petrenko, G Ekinil, 2020 [23,24,25]. 
The following methods were used when conducting the research: statistical data processing, comparative analysis, spatial analysis of the territory, economic, sociological, predictive methods.

\section{Results}

Innovations play an oversize role in the development of the economics and the society as a whole. The term "innovation" has no unambiguous interpretation. This concept was introduced into scientific discourse by the Austrian scientist J. Schumpeter in the first decade of the XX century. This definition means a new product, a new phenomenon or action on the market (enterprise), which aims to attract a consumer, satisfy his or her needs and produce income to an entrepreneur. The current need of the Russian economy for innovation is extremely urgent, and tourism is no exception. This industry is considered to be one of the most highly profitable and dynamically developing. Ever-changing conditions for the functioning of the tourist market require its participants to quickly adapt and update. Innovations in the tourism industry are mainly focused on the formation of a new tourism product, new approaches to marketing activities, as well as the application of new management methods using IT technologies. The modern tourism industry, like many other activities, is influenced by digital technologies.

Digitalization promotes the development of regional, including rural, tourism. New digital technologies that facilitate travels boost an inflow of tourists to the regions. According to the Federal Agency of Tourism of Russia, 25\% of tourists travel independently and these values are constantly increasing. More and more travelers want to organize their holidays on their own. Tourists, without recourse to tour agents and tour operators, book tickets for transport, hotel rooms and use various mobile applications maps, travel guides, audio guides, and translators. Mobile excursion applications play an important role in the development of regional tourism. Mobile excursion applications are a relatively new area for the development of independent tourism. Development, implementation and promotion among tourists help to increase the tourist attractiveness of the territory. A mobile application is a software designed to run on smartphones, tablets and other mobile devices, and developed for a specific platform, which can be initially installed or downloaded from special online applications (APP Store, Google Play) on a paid or free basis.

The research methodology of this issue is still in the stage of formation. However, the object and subject of research in this area have been already identified, the problematic area has been identified, and methodological tools are being formed. Important issues in the study of this problem are:

- assessment of the technical possibilities of using mobile applications, namely, the availability of modern mobile phones for the population with the ability to install mobile applications;

- analysis of the coverage of territory by the mobile Internet, necessary for the use of mobile applications and its cost availability for the population;

- availability of mobile touristic and excursion applications in the studied region;

- study of the application statistics, the application downloadableness and the number of repeated calls to it;

- study of the dynamics of the main characteristics of application users (age, place of residence).

As mobile applications are rapidly gaining popularity, there is a need to regulate this area. So, in Russia in 2018, the Russian quality system developed a standard for mobile applications. It has the PNST 277-2018 (National prestandard 277-2018) marking and the name "Russian quality system. Comparative tests of mobile applications for smartphones". 
The standard contains 87 quality requirements for mobile applications, including performance, functionality, usability and safety. Among the requirements there is, for example, free trial for paid programs. But all these requirements are only advisory in nature.

The development of mobile applications influences the flow of independent tourists, as well as vice versa - the growth of independent tourism promotes the emergence and improvement of mobile applications in tourism. Prospects for the mobile touristic applications market are related to the installation of free Wi-Fi points in various places of the city, the active development of mobile Internet and its relatively inexpensive cost. Russia is one of the ten countries with the cheapest mobile Internet - at the average rate of 65.2 rubles per $1 \mathrm{~GB}$ of traffic. As a comparison, in Japan the same amount of traffic costs 830.7 rubles. As of the beginning of 2019, the number of mobile Internet users amounted to $75.4 \%$ of the adult population of Russia. Of these, $41 \%$ are in the $16-29$ age group, $30 \%$ are in the 30-54 age group and 9\% are over 55 years old. High degree of availability of mobile devices to the population of Russia should be noted too. In Russia in 2018, 78.9 million people were the owners of smartphones. This means that most of the adult population owns at least one mobile device. The largest number of mobile excursion applications has been developed for Moscow and St. Petersburg. According to the Play Market platform for smartphones based on Android, there are more than one hundred such applications for these cities.

\section{Discussion}

Mobile applications for rural areas are of particular importance. Such types of tourism as business, cultural and educational, ethnographic, water, event and others are developed in the Rostov region. Most of the territory of the Rostov region is of the rural type. The rural landscape is characterized by picturesque views, favorable climate and an abundance of natural tourism and recreational resources. The rural areas have a great tourism potential. The Rostov region has enough prerequisites and various conditions for the development of rural tourism. A significant part of the territory is of the agricultural type. Many sectors of crop growing and animal farming are developed here. Also, the territory of the Rostov region is distinguished by ethnic diversity, which results in the unique cultural and historical traditions of the local population. In many territories, the rural way of life dominates. However, the infrastructure of rural areas is underdeveloped to accommodate a large number of tourists. At the same time, small but stable tourist flows could revive the economy and socio-cultural life of rural areas.

Mobile touristic and excursion applications for smartphones for these territories could become one of the significant factors in attracting tourists to rural areas. An analysis of existing applications showed that there are only three applications containing an excursion component for the city of Rostov-on-Don and the Rostov region. At that, the listed areas have a great tourism potential. More than 1 million tourists visit Rostov-on-Don and the Rostov region annually. And these values continue to grow.

This is promoted by a favorable geographical position, well-developed transport infrastructure, natural resources and rich historical and cultural heritage. It is the region that has a high level of independent tourism. This is due to the transit position of the territory. The region is located at the intersection of the largest transport routes. A huge flow of travelers comes from the central and northern regions of Russia to the Black Sea coast, the Caucasus and Crimea year on year. Staying in Rostov-on-Don, tourists often make excursions around the city and the surrounding areas. However, they often use mobile excursion applications and audio guides. 
As of 2020, the Play Market application for smartphones contains only 3 mobile excursion applications (Rostov-on-Don Travel Guide Tourism, Velovod and REQUEST), and only one of them - the REQUEST application - has excursion routes. On the official portal concerned with tourism in the Rostov region, there are also electronic guides to the main tourist places of the region. However, they are not presented by mobile versions.

The interest in self-guided excursions using mobile applications in Rostov-on-Don and the Rostov region can be traced on the example of the mobile excursion application "REQUEST", launched in 2017. The "REQUEST" application is distinguished by the most convenient and rich package of excursions and quests. The application is free to install and use all excursions and quests. This application is a software and hardware complex, consisting of the following elements: database, administrator panel and software.

1. Database, which is the main element of the system. The database contains routes for city tours and quests. The database is hosted on a specialized php server. The database is open-sourse software, allowing any user to work with this server. The application database is enabled by the Symfony framework.

2. Administrator Panel. This is the workplace of the Administrator, who adds all information related to the texts of excursions and quests, routes, photographs of objects and others to the database. From the architectural perspective, the Administrator Panel is an angularJS framework. The Administrator's access to the Administrator Panel is enabled by WEB-Interface.

3. Application based on Android and IOS. Mobile application - Software. The application contains the structure of the software (basic elements of excursions, quests, etc.). In addition, the software establishes a connection with the payment system and other external services (cards, push notifications, etc.) Android application is enabled by kotlin, IOS application is enabled by swift.

The scheme of the "REQUEST" application is presented as follows: a user downloads the application on the PlayMarket for Android or on the AppStore for IOS to their mobile device.

The scheme of the Administrator's operation is the entry to the Administrative Panel through the WEB-Interface making changes to the Database. The database stores all information and transmits it via the Internet at the request of the Application. The application contains a number of excursion routes, a large number of high quality photographs of excursion objects. All points of the excursion route are geolocated, i.e. binding to the map, so that it is easier for the tourist to navigate the area.

The second important part of the content of this Application is quests. As practice shows, quest tourism has great prospects. This type should promote domestic tourism, including rural tourism, get different age groups of the population interested. Most modern residents of large cities are sedentary, so quests can satisfy their needs for activity and adventure.

Initially, $50 \%$ of excursions were made as paid content. Having studied the ratio of downloads of paid and free excursions, the authors concluded that paid excursions are not popular, because $75 \%$ of the excursions downloaded from the mobile application were free. Paid content accounted for only $25 \%$. Paid excursions were practically not in demand by consumers, even with an excursion price of 50-100 rubles. This suggests that at this stage in Rostov-on-Don, consumers are not yet ready to pay for such services. Currently, all excursions and quests are free; the application has ceased to be a commercial project and now works on the initiative of the authors.

The analysis of the dynamics of the use of the "REQUEST" application made it possible to identify trends in the growth of its popularity. So, for the period from 2017 to 2019, the number of application users increased from 200 to 2700 , i.e. there was an increase of 13.5 times. 


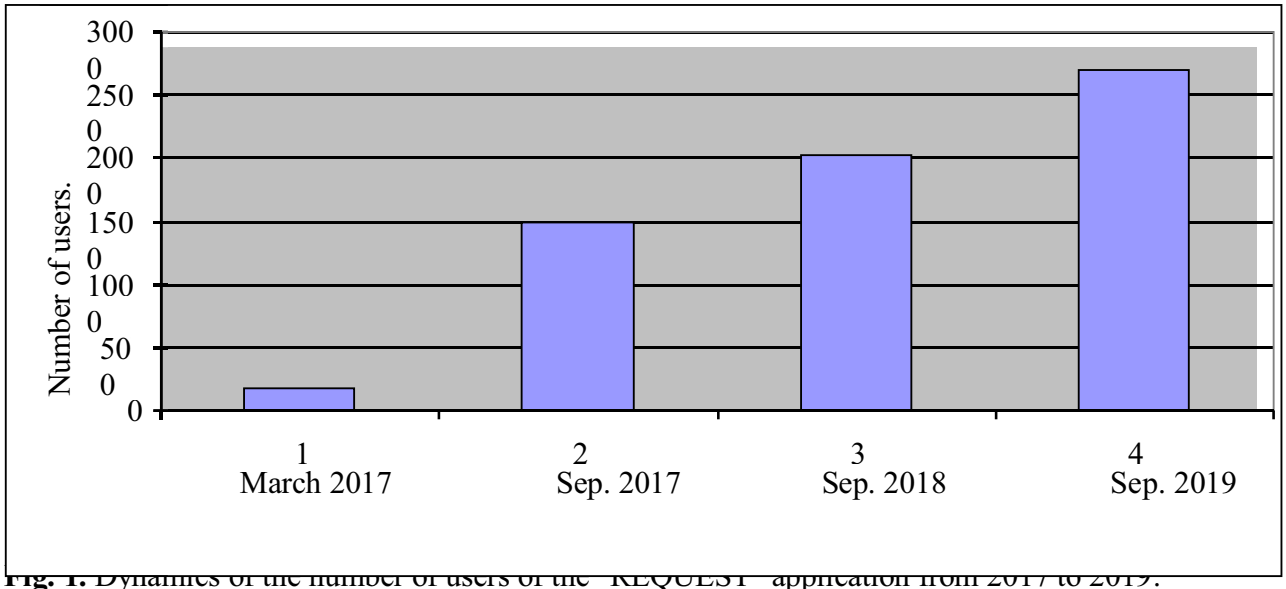

The chart shows the fastest growth in the first 6 months of the application launch. On average, the annual user growth rate is $30 \%$. This points to the need for this application.

There are foreign citizens among the users of the application. Unloading the reporting data of the application allows you to analyze the dynamics of their number and share in the overall structure of users. The presented graph shows that the highest growth rates of foreign users are typical for the summer period of 2018. It was the time the FIFA World Cup was held in Rostov-on-Don, which was attended by a large number of foreign tourists. From 2017 to 2018, the number of foreign users increased 2.6 times, and from 2018 to 2019 only 0.9 times.

As far as the geography of foreign users, most of them are from the United States - 54\% (Figure 2). The second largest category are citizens of Ukraine - 20\%, followed by citizens of China (7\%), Hong Kong (6\%), Turkey (4\%), Switzerland (1\%). The remaining category $(8 \%)$ includes such countries as Belarus, Montenegro, Greece, the Netherlands, Germany, Georgia, Palestine and Taiwan.

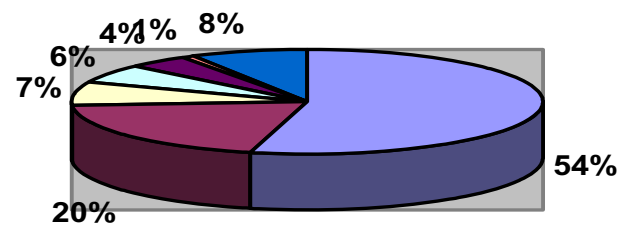

\section{$\square$ USA $\square$ Ukraine $\square$ China $\square$ Hong Kong $\square$ Turkey}

Fig. 2. Country-specific structure of foreign users of the "REQUEST" application.

An important indicator, which was studied by the authors, was the growth rate of the number of foreign users of the REQUEST touristic and excursion application. This shows that the absolute number of foreign users has a steady growth rate. This indicates that this application is of interest not only for domestic tourists, but also for foreign tourists (Figure $3)$. 


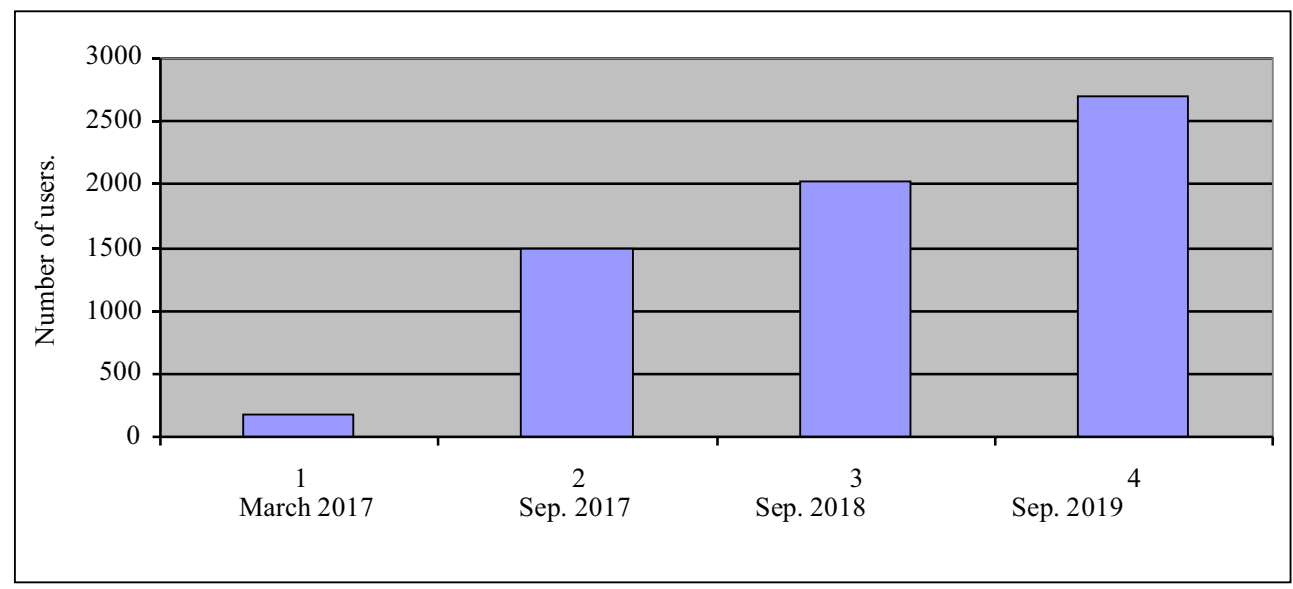

Fig. 3. Growth rate of foreign users of the REQUEST application.

An important parameter of the study in this paper was the age of the users of this application. An analysis of the age structure of the users and the topic of downloaded excursions showed that people in the age category over 50 are more were interested in classical educational excursions representing the history of the area and thematic directions related to territorial specifics (for example, the theme of the Cossackdom, the Civil War, the Great Patriotic War, history of the city and region). A younger audience is attracted by quests and modern topics in excursions (sports, cultural and leisure, music). This means that the development of mobile applications should be largely focused at the interests of the most active part of the population. But this does not exclude the development of applications and their modifications for less active groups of users.

In this paper, a sociological study was also carried out by exploring the views of users through feedbacks in available sources of the Internet. The exploration of user reviews on the site of the REQUEST mobile application showed that there is a need to expand the list of excursions and topics for the city of Rostov-on-Don, as well as for the Rostov region and especially in rural areas. Particular attention should be paid to virtual excursions in rural areas, because this is often almost the only form of excursions. While there is organized tourism in large cities through local travel agencies, it is not true for rural areas.

The authors of this study, together with the developers of the REQUEST touristic and excursion application, identified consumer preferences in the territories of the Rostov region, where tourists would like to receive virtual excursions. The ratio of needs for excursions for different territories is shown in Figure 4. 


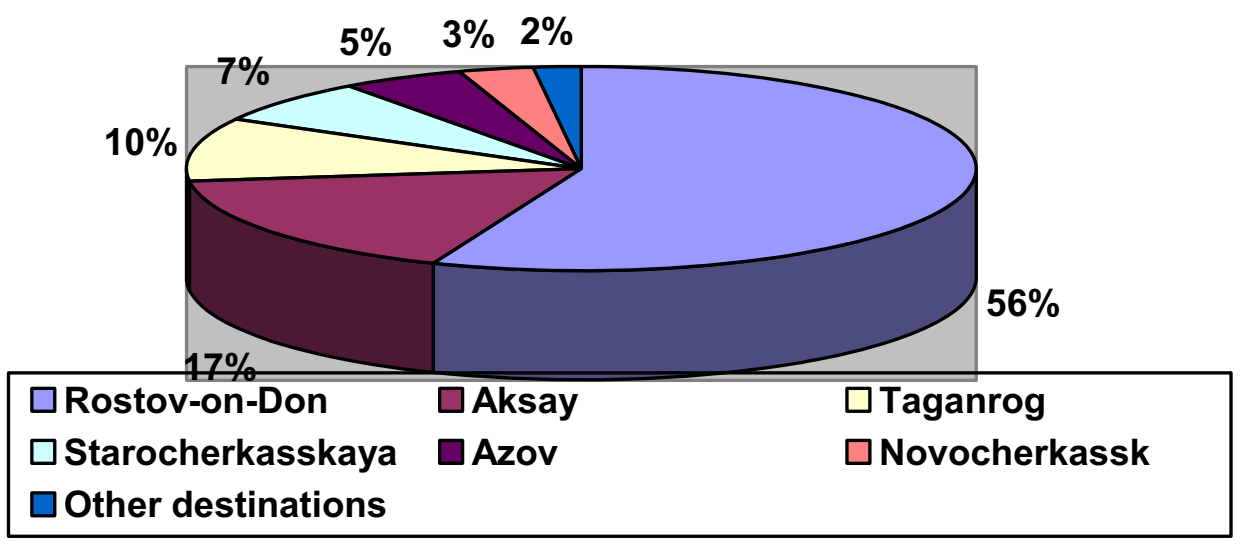

Fig. 4. The need for excursion routes in the REQUEST application based on consumer feedbacks.

As the figure shows, tourists tend to see offers for excursions to such cities as Rostovon-Don (56\%), Aksay (17\%), Taganrog (10\%), Starocherkassk (7\%), Azov (5 \%), Novocherkassk (3\%) and various rural areas $(2 \%)$ in the list of excursions.

Moreover, the authors of the article conducted a sociological study regarding the use of mobile excursion applications. 100 people of each age category were interviewed: 18-30 years old; 31-50 years old; over 51 years old in equal proportions. Based on the results, the main limiting factors in the development of mobile applications related to tourism in Rostov-on-Don were identified:

- ignorance of users. Most of the respondents at the age over 50 (68\%) use a mobile phone only for calls and SMS, being foggy on features of mobile applications. $26 \%$ of the $31-50$ age group and $6 \%$ of the 18-30 age group have no idea of mobile applications;

- difficulty in installation and use. $34 \%$ of respondents do not use mobile applications due to technical difficulties or lack of smartphone power;

- fear of using online payment for applications and services, distrust in the transmission of payment card data $(17 \%)$;

- lack of interest in mobile excursion applications. In this category, the maximum number of respondents who are not interested in this issue is typical for the 18-30 age group (57\%). The most interested group is $31-50$ (11\%); among, $42 \%$ of the respondents over 50 years old are not interested in excursion applications.

\section{Conclusions}

Based on the results of the conducted study a number of conclusions can be made:

1. Mobile applications are gaining popularity in Russia. This is pushed by such factors as the inexpensive cost of mobile Internet, wide mobile Internet coverage of the territory, a high level of mobile devices availability (smartphones and tablets) to the population and the continued growth of their active use.

2. The insufficient level of use of mobile applications is associated with ignorance of users in terms of features of mobile devices and the availability of such applications in general, as well as the fear of using payment systems in smartphones and tablets.

3. Mobile touristic applications can attract independent tourists to the region by making it easier to book tickets for transport, hotel rooms, using online travel guides, translators, maps and audio guides. 
4. The market of mobile excursion applications in Rostov-on-Don and the Rostov region is at an early stage of development. Of the 7 touristic applications presented in the Play Market platform, only 3 have guides and routes with geolocation.

5. In the authors' opinion, in order to attract more tourists to the region, it is necessary to intensify the interaction of mobile application developers with the Tourism Division of the Department of Economics of Rostov-on-Don, with administrations of rural territories, with tourist information centers, touristic and excursion enterprises of the city, specialized colleges and universities. The application should also be promoted in touristic markets, and be included in the guidebooks for the region.

6. The REQUEST mobile application requires an increase in the number of excursions and quests, expansion of the geography of routes, especially in rural areas, differentiation of offers by age categories, as well as coinciding the theme of excursions and quests with newsworthy events. This will make it possible to attract additional tourist flows to the region and intensify regional tourism, including rural tourism.

\section{References}

1. S. Park, Y. Xu, Liu Jiang, Zhelin Chen, Shuyi Huang, Annals of Tourism Research 84, 102973 (2020) https://doi.org/10.1016/j.annals.2020.102973

2. Hai-Ninh Do, Wurong Shih, Quang-An Ha, Research article 6(8), e04667 (2020) https://doi.org/10.1016/j.heliyon.2020.e04667

3. J. Reif, D. Schmücker, Journal of Destination Marketing \& Management 18, 100481 (2020) https://doi.org/10.1016/j.jdmm.2020.100481

4. H. Bicen, S. Sadiko glu, Procedia Economics and Finance 39, 270-274 (2016)

5. M. Devita, I. Mochamad, R. Hidayat, N. Viani, A. Dewi Suryani, Procedia Computer Science 116, 556-563 (2017) https://doi.org/10.1016/j.procs.2017.10.059

6. Chia-Chen Chen, Jia-Lun Tsai, Future Generation Computer Systems 96, 628-638 (2019) https://doi.org/10.1016/j.future.2017.02.028

7. V. Veréb, A. Azevedo, Journal of Hospitality and Tourism Management 41, 208-218 (2019) https://doi.org/10.1016/j.jhtm.2019.10.003

8. Á. Martínez-Pérez, D. Elche, P.M.García-Villaverde, Journal of Destination Marketing \& Management 11, 80-88 (2019) https://doi.org/10.1016/j.jdmm.2018.12.002

9. I. Kofler, A. Marcher, M. Volgger, H. Pechlaner, Journal of Hospitality and Tourism Management 37, 68-75 (2018) https://doi.org/10.1016/j.jhtm.2018.09.004

10. B. Casais, J. Fernandes, M. Sarmento, Journal of Hospitality and Tourism Management 42, 51-57 (2020) https://doi.org/10.1016/j.jhtm.2019.11.010

11. Myung Ja Kim, Choong-Ki Lee, M.W. Preis, Telematics and Informatics 49, 101349 (2020) https://doi.org/10.1016/j.tele.2020.101349

12. Marcus Hansen, Anne-Mette Hjalager, Alan Fyall, Journal of Outdoor Recreation and Tourism, 28, 100253 (2019) https://doi.org/10.1016/j.jort.2019.100253

13. B. Pikkemaat, M. Peters, B. Fabian Bichler, Journal of Hospitality and Tourism Management 41, 184-196 (2019)

14. O. Broshi-Chen, Y. Mansfeld, Journal of Hospitality and Tourism Management 46, 272-283 (2021) https://doi.org/10.1016/j.jhtm.2021.01.003 
15. S. Karampela, D. Kavroudakis, T. Kizos, Current Issues in Tourism 22(12), 14601479 (2019)

16. N.T. Farsani, S.S. Ghotbabadi, M. Altafi, Asia Pacific Journal of Tourism Research 24(6), 541-549 (2019)

17. R.M. Back, A.D.A. Tasci, A. Milman, Journal of Vacation Marketing 26(1), 57-72 (2020)

18. H. Choo, J.F. Petrick, Tourism Management 40, 372-381 (2014) doi: 10.1016/j.tourman.2013.07.011

19. A.R.D. Liang, Y.Y. Nie, D.J. Chen, P.-J. Chen, Journal of Hospitality and Tourism Management 42, 107-118 (2020)

20. M.V. Vikhoreva, Yu.N. Malanina, V.A. Ogloblin, IOP Conference Series: Earth and Environmental Science 421(2), 022039 (2020)

21. M.S. Giltsova, O.A. Mironova, Modern fundamental and applied research 1(32), 7075, (2019)

22. A.V. Truhachev, Service in Russia and abroad 10(3), 260-275, (2016) doi: $10.12737 / 20116$

23. L.N. Kazmina, V.S. Makarenko, V.V. Provotorina, T.N. Grigorenko, International Journal of Economics and Business Administration 7, 510-520 (2019) doi: $10.35808 / \mathrm{ijeba} / 297$

24. L. Kazmina, V. Makarenko, V. Provotorina, E. Shevchenko, E3S Web of Conferences 175, 10001 (2020)

25. V. Provotorina, L. Kazmina, A. Petrenko, G Ekinil, E3S Web of Conferences 175, 10002 (2020) 